Disponível em

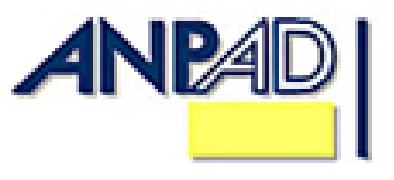

http://www.anpad.org.br/rac

RAC, Curitiba, v. 15, n. 4,

pp. 731-747, Jul./Ago. 2011

$(\infty)$ EY-No

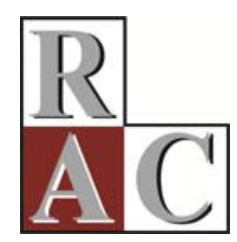

Documentos e Debates:

\title{
Análise de Conteúdo como Técnica de Análise de Dados Qualitativos no Campo da Administração: Potencial e Desafios
}

\section{Content Analysis as a Qualitative Data Analysis Technique in the Field of Administration: Potentials and Challenges}

Anelise Rebelato Mozzato *

E-mail: anerebe@terra.com.br Universidade de Passo Fundo - FEAC/UPF

Passo Fundo, RS, Brasil.

Denize Grzybovski

E-mail: gdenize@upf.br

Universidade de Passo Fundo - FEAC/UPF

Passo Fundo, RS, Brasil.

* Endereço: Anelise Rebelato Mozzato

Rua Adolfo Loureiro, 190, apto. 401, Bairro Lagoa do Potreiro, Passo Fundo/RS, 99010-650.

Copyright (C) 2011 RAC. Todos os direitos, até mesmo de tradução, são reservados. É permitido citar parte de artigos sem autorização prévia, desde que seja identificada a fonte. 


\section{Introdução}

No campo da produção científica de Administração, há crescente interesse pela análise de conteúdo como técnica de análise de dados que, nos últimos anos, vem tendo destaque entre os métodos qualitativos, ganhando legitimidade. A importância da análise de conteúdo para os estudos organizacionais é cada vez maior e tem evoluído em virtude da preocupação com o rigor científico e a profundidade das pesquisas. No entanto, a constituição de novos paradigmas científicos impõe outras dinâmicas também à análise dos dados das pesquisas científicas. De modo geral, as transformações sucessivas pelas quais têm passado a ciência evidenciam irregularidades e também rupturas, sobretudo no que tange às ciências sociais, que exigem revisitar as abordagens metodológicas. Nessa lógica se insere a análise de conteúdo, a qual cada vez mais conquista legitimidade nas pesquisas qualitativas no campo da administração, razão por que deve entrar na pauta das discussões científicas.

Diante dessa realidade, o objetivo geral deste ensaio teórico é realizar uma discussão a respeito da técnica análise de conteúdo, perpassando por questões centrais, tais como: Em que sentido a análise de conteúdo contribui para as pesquisas qualitativas no campo da administração? Quais os atuais desafios dessa perspectiva? A análise de conteúdo pode fazer parte de uma visão mais ampla, para além da influência positivista que sofre? Dessa forma, apresenta-se a análise de conteúdo como técnica de análise de dados rica, importante e com potencial para o desenvolvimento teórico do campo da administração. Entretanto, este texto direciona-se no sentido de analisar criticamente as controvérsias e as potencialidades do método na pesquisa qualitativa em administração.

Inicialmente, pode-se dizer que análise de conteúdo é uma técnica refinada, que exige muita dedicação, paciência e tempo do pesquisador, o qual tem de se valer da intuição, imaginação e criatividade, principalmente na definição de categorias de análise. Para tanto, disciplina, perseverança e rigor são essenciais (Freitas, Cunha, \& Moscarola, 1997).

O percurso de análise deste trabalho toma como referência a obra de Laurence Bardin, literatura de referência atualmente em análise de conteúdo. No entanto, outros autores servem de base no transcorrer do texto visando atingir o objetivo proposto, a fim de tentar dar resposta aos questionamentos levantados inicialmente. Com esse intuito, realizou-se pesquisa bibliográfica que teve como objetivo dedicar ao tema um olhar aprofundado e crítico confrontando aspectos identificados como relevantes para essa discussão.

Em razão de a utilização da análise de conteúdo estar crescendo no Brasil, principalmente nas pesquisas que se caracterizam por abordagem predominantemente qualitativa (Dellagnelo \& Silva, 2005), torna-se evidente a validade de reflexões acerca desta técnica. No entanto, cabe salientar que não se tem como proposta a discussão da técnica em si, o que já foi realizado por muitos autores internacionais (Clegg, Hardy, \& Nord, 2001; Denzin \& Lincoln, 2000) e nacionais (Godoi, Bandeirade-Melo, \& Silva, 2006; Mattos, 2001, 2006; Vergara, 2003). Pretende-se sim, trabalhar os desafios que tal técnica ainda apresenta ao ser trabalhada em perspectiva mais ampla, para além da influência positivista. Dessa forma, acredita-se que este ensaio teórico pode ser de grande utilidade tanto para os pesquisadores do campo da administração que já vêm utilizando a técnica, como para aqueles que pretendem vir a utilizá-la, pois se sabe que muitos se aventuram na sua aplicação em razão da sua visibilidade e credibilidade no meio científico, porém não a conhecem de fato.

Contudo, inicia-se a discussão pela conceituação e procedimentos da técnica análise de conteúdo com o intuito de explicitá-la. Dessa forma, apresenta-se um breve panorama histórico, salientando, na sequência, a pertinência da análise de conteúdo das pesquisas qualitativas em administração. A seguir, são esboçadas algumas das diferentes técnicas de análise de dados utilizadas nos estudos organizacionais. Logo após, relatam-se debates contemporâneos e críticos em relação à análise de conteúdo, salientando a importância da técnica pelo destaque de suas potencialidades e limitações, bem como validade e confiabilidade, essenciais para a legitimação da pesquisa científica. Nesse sentido, também se aborda a respeito das novas tecnologias (softwares) como facilitadoras da 
análise de dados qualitativos. Por fim, destacam-se as possibilidades da utilização da análise de conteúdo no campo da administração e apresentam-se as conclusões do presente trabalho.

Neste ensaio teórico não se tem a pretensão de desenvolver um overview da técnica análise de conteúdo, no sentido de apresentar vasta revisão de literatura a respeito do método em si (procedimentos). Trata-se, sim, de um estudo que aborda a origem da técnica, recuperando alguns debates contemporâneos e críticos no que tange a sua aplicação no campo da administração, visando apontar suas possibilidades para este. Em suma, tem-se como propósito maior a contribuição para os estudos acerca das técnicas de análise de dados no âmbito da pesquisa de administração, abordando uma estratégia de análise já muito utilizada e promissora para o avanço do conhecimento no campo em suas diferentes áreas temáticas.

\section{Análise de Conteúdo: Pertinência às Pesquisas Qualitativas em Administração}

Sem desconsiderar a importância das etapas anteriores à análise científica de dados, este ensaio teórico tem como foco refletir sobre as particularidades na análise de dados pela técnica análise de conteúdo. Há diferentes técnicas que podem ser utilizadas na execução de pesquisas diferenciadas, mas a análise de conteúdo consiste numa técnica de análise de dados que vem sendo utilizada com frequência nas pesquisas qualitativas no campo da administração, assim como na psicologia, na ciência política, na educação, na publicidade e, principalmente, na sociologia. Na realidade, como refere Flick (2009), a pesquisa qualitativa é recente e ocorreu concomitantemente em diversas áreas, tendo-se cada uma delas caracterizado por um embasamento teórico específico, por conceitos de realidade específicos e por seus próprios programas metodológicos.

Qualquer técnica de análise de dados, em última instância, significa uma metodologia de interpretação. Como tal, possui procedimentos peculiares, envolvendo a preparação dos dados para a análise, visto que esse processo "consiste em extrair sentido dos dados de texto e imagem” (Creswell, 2007, p. 194). Contudo, entre as diferentes estratégias analíticas os processos e os termos diferem, e a análise de conteúdo também apresenta peculiaridades.

Em relação à escolha do procedimento de análise de dados:

A descodificação de um documento pode utilizar-se de diferentes procedimentos para alcançar o significado profundo das comunicações nele cifradas. A escolha do procedimento mais adequado depende do material a ser analisado, dos objetivos da pesquisa e da posição ideológica e social do analisador (Chizzotti, 2006, p. 98).

Nesse sentido, quando a análise de conteúdo é escolhida como procedimento de análise mais adequado, como em qualquer técnica de análise de dados, os dados em si constituem apenas dados brutos, que só terão sentido ao serem trabalhados de acordo com uma técnica de análise apropriada. Para Flick (2009), a análise de conteúdo, além de realizar a interpretação após a coleta dos dados, desenvolve-se por meio de técnicas mais ou menos refinadas. Dessa forma, a análise de conteúdo se vem mostrando como uma das técnicas de análise de dados mais utilizada no campo da administração no Brasil, especialmente nas pesquisas qualitativas (Dellagnelo \& Silva, 2005).

Pelo fato de este ensaio teórico privilegiar a análise qualitativa, aspectos gerais a respeito são abordados no seu desenvolvimento, considerando, sobretudo, as pesquisas de Denzin e Lincoln (2000, 2006, 2008). Os autores ressaltam que também no século XXI a pesquisa qualitativa precisa fazer parte da agenda acadêmica como geradora de resultados das investigações científicas e que pode ser trabalhada no sentido de repensar e criar uma sociedade livre e democrática, revelando o seu caráter crítico (Denzin \& Lincoln, 2000).

Entre outros pesquisadores, Shah e Corley (2006) apontam a importância e a validade da pesquisa qualitativa, demonstrando que acreditam no seu crescimento e aceitação. Os autores 
incentivam a complementaridade dos métodos qualitativos e quantitativos, ressaltando que os estudos organizacionais têm muito a ganhar, ao utilizarem concomitantemente os dois métodos. Ainda referem que pontos negativos estão sendo superados em relação à pesquisa qualitativa, além de que a metodologia está cada vez se mostrando mais consistente, o que muito se deve ao rigor científico que tem demonstrado.

\section{Conceito e procedimentos da análise de conteúdo}

Cabe salientar que, por mais que muitos autores abordem a análise de conteúdo, até mesmo utilizando conceitos diferenciados e diferentes terminologias para as diversas etapas da técnica, neste ensaio teórico toma-se como base a conceituação de Bardin (2006), bem como as etapas da técnica explicitadas por este autor. Tal opção se deve a que o autor é o mais citado no Brasil em pesquisas que adotam a análise de conteúdo como técnica de análise de dados. Bardin (2006, p. 38) refere que a análise de conteúdo consiste em:

um conjunto de técnicas de análise das comunicações, que utiliza procedimentos sistemáticos e objectivos de descrição do conteúdo das mensagens. ... A intenção da análise de conteúdo é a inferência de conhecimentos relativos às condições de produção (ou eventualmente, de recepção), inferência esta que recorre a indicadores (quantitativos ou não). (tradução nossa)

Diante do exposto, percebe-se que a análise de conteúdo é um conjunto de técnicas de análise de comunicações, que tem como objetivo ultrapassar as incertezas e enriquecer a leitura dos dados coletados. Como afirma Chizzotti (2006, p. 98), “o objetivo da análise de conteúdo é compreender criticamente o sentido das comunicações, seu conteúdo manifesto ou latente, as significações explícitas ou ocultas”.

Dentre as comunicações, Bauer e Gaskell (2008) indicam que os materiais textuais escritos são os mais tradicionais na análise de conteúdo, podendo ser manipulados pelo pesquisador na busca por respostas às questões de pesquisa. Com abordagem semelhante, Flick (2009, p. 291) afirma que a análise de conteúdo "é um dos procedimentos clássicos para analisar o material textual, não importando qual a origem desse material”.

Existem diversas formas de documentação do material coletado, na maioria das vezes constituindo-se de material textual: notas de campo, diário de pesquisa, fichas de documentação, transcrição etc. Entretanto, o material também pode ser documentado por meio de fotos, filmes, áudios e outros, pois todas as formas de documentação têm relevância no processo de pesquisa, possibilitando uma adequada análise (Flick, 2009).

Como a análise de conteúdo constitui uma técnica que trabalha os dados coletados, objetivando a identificação do que está sendo dito a respeito de determinado tema (Vergara, 2005), há a necessidade da descodificação do que está sendo comunicado. Para a descodificação dos documentos, o pesquisador pode utilizar vários procedimentos, procurando identificar o mais apropriado para o material a ser analisado, como análise léxica, análise de categorias, análise da enunciação, análise de conotações (Chizzotti, 2006, p. 98).

Para Minayo (2001, p. 74), a análise de conteúdo é "compreendida muito mais como um conjunto de técnicas”. Na visão da autora, constitui-se na análise de informações sobre o comportamento humano, possibilitando uma aplicação bastante variada, e tem duas funções: verificação de hipóteses e/ou questões e descoberta do que está por trás dos conteúdos manifestos. Tais funções podem ser complementares, com aplicação tanto em pesquisas qualitativas como quantitativas.

O processo de análise de dados em si envolve várias etapas para auferir significação aos dados coletados (Alves-Mazzotti \& Gewandsznajder, 1998; Creswell, 2007; Flick, 2009; Minayo, 2001), o que não é diferente na análise de conteúdo. No que se refere às diferentes etapas inerentes à análise de conteúdo, autores utilizam diferentes terminologias, as quais são bastante semelhantes (Triviños, 
1987). Diante dessa diversificação e também aproximação terminológica, optou-se por elencar as etapas da técnica segundo Bardin (2006), o qual as organiza em três fases: 1) pré-análise, 2) exploração do material e 3) tratamento dos resultados, inferência e interpretação.

A pré-análise é a fase em que se organiza o material a ser analisado com o objetivo de torná-lo operacional, sistematizando as ideias iniciais. Trata-se da organização propriamente dita por meio de quatro etapas: (a) leitura flutuante, que é o estabelecimento de contato com os documentos da coleta de dados, momento em que se começa a conhecer o texto; (b) escolha dos documentos, que consiste na demarcação do que será analisado; (c) formulação das hipóteses e dos objetivos; (d) referenciação dos índices e elaboração de indicadores, que envolve a determinação de indicadores por meio de recortes de texto nos documentos de análise (Bardin, 2006).

A exploração do material constitui a segunda fase, que consiste na exploração do material com a definição de categorias (sistemas de codificação) e a identificação das unidades de registro (unidade de significação a codificar corresponde ao segmento de conteúdo a considerar como unidade base, visando à categorização e à contagem frequencial) e das unidades de contexto nos documentos (unidade de compreensão para codificar a unidade de registro que corresponde ao segmento da mensagem, a fim de compreender a significação exata da unidade de registro). A exploração do material consiste numa etapa importante, porque vai possibilitar ou não a riqueza das interpretações e inferências. Esta é a fase da descrição analítica, a qual diz respeito ao corpus (qualquer material textual coletado) submetido a um estudo aprofundado, orientado pelas hipóteses e referenciais teóricos. Dessa forma, a codificação, a classificação e a categorização são básicas nesta fase (Bardin, 2006).

A terceira fase diz respeito ao tratamento dos resultados, inferência e interpretação. Esta etapa é destinada ao tratamento dos resultados; ocorre nela a condensação e o destaque das informações para análise, culminando nas interpretações inferenciais; é o momento da intuição, da análise reflexiva e crítica (Bardin, 2006).

Tendo em vista as diferentes fases da análise de conteúdo proposta por Bardin (2006), destacam-se como o próprio autor o fez, as dimensões da codificação e categorização que possibilitam e facilitam as interpretações e as inferências. No que tange à codificação, "corresponde a uma transformação - efectuada (sic) segundo regras precisas - dos dados brutos do texto, transformação esta que, por recorte, agregação e enumeração, permite atingir uma representação do conteúdo, ou da sua expressão" (Bardin, 2006, p. 103). Após a codificação, segue-se para a categorização, a qual consiste na:

classificação de elementos constitutivos de um conjunto, por diferenciação e, seguidamente, por reagrupamento segundo o gênero (analogia), com os critérios previamente definidos. As categorias, são rubricas ou classes, as quais reúnem um grupo de elementos ... sob um título genérico, agrupamento esse efectuado em razão dos caracteres comuns destes elementos (Bardin, 2006, p. 117).

Cabe salientar que tais etapas envolvem diversos simbolismos que precisam ser descodificados. Para tanto, o pesquisador precisa fazer um esforço para desvendar o conteúdo latente, como refere Triviños (1987, p. 162). Nesse sentido, a análise contextual e histórica é de grande valia (Bateson, 2000; Thompson, 1995), além da criatividade, intuição e crítica (Bardin, 2006; Thompson, 1995). Denzin e Lincoln (2000) enfatizam o papel do caráter crítico da pesquisa.

No que tange às fases da análise de conteúdo propostas por Bardin (2006), outros autores propõem fases semelhantes, apenas com algumas particularidades diferenciais que não alteram o processo em si. A exemplo, cita-se Flick (2009, pp. 292-293), o qual, com base em Mayring (1983), delineia os seguintes passos para a análise de conteúdo: síntese da análise de conteúdo, por meio da omissão de enunciados; análise explicativa de conteúdo, com o esclarecimento de trechos difusos, ambíguos ou contraditório; por fim, a análise estruturadora de conteúdo, por meio da estruturação no nível formal relativo ao conteúdo. 
Também Triviños (1987) lista as diferentes fases, utilizando-se da classificação de Bardin, porém diferenciando-se em alguma nomenclatura e salientando alguns aspectos da própria teoria do autor. Assim, denomina as fases como pré-análise, descrição analítica e interpretação inferencial, chamando a atenção para um fato:

Não é possível que o pesquisador detenha sua atenção exclusivamente no conteúdo manifesto dos documentos. Ele deve aprofundar sua análise, tratando de desvendar o conteúdo latente que eles possuem. .... Os investigadores que só ficam no conteúdo manifesto dos documentos seguramente pertencem à linha positivista (Triviños, 1987, p. 162).

Entretanto, por mais que se devam respeitar certas "regras" e que se salientem as diferentes fases e etapas no emprego, a análise de conteúdo não deve ser considerada e trabalhada como modelo exato e rígido. Mesmo Bardin (2006) rejeita esta ideia de rigidez e de completude, deixando claro que a sua proposta da análise de conteúdo acaba oscilando entre dois polos que envolvem a investigação científica: o rigor da objetividade, da cientificidade, e a riqueza da subjetividade. Nesse sentido, a técnica tem como propósito o ultrapassar o senso comum do subjetivismo e alcançar o rigor científico necessário, mas não a rigidez inválida, que não condiz mais com tempos atuais.

\section{Aspectos históricos e importância da análise de conteúdo}

Apesar de precedentes históricos, foi em 1927 que Harold Laswell começou a trabalhar com a análise de conteúdo, estudando a propaganda na Primeira Guerra Mundial. Nessa época a linguística e a análise de conteúdo não se conversavam, por mais que tivessem a linguagem como objeto de estudo semelhante. Em 1940 e 1950 o método de análise de conteúdo despertou interesse, o que levou a seu maior desenvolvimento (Richardson, 1999). Foi justamente nessas décadas que Berelson, auxiliado por Lazarsfed, desenvolveu estudos mais aprofundados a respeito da análise de conteúdo (Bardin, 2006). Contudo, também outros estudos, tanto americanos como franceses, foram realizados no sentido de aprimoramento da técnica.

Assim, em 1977, Bardin publicou a sua obra L'analyse de contenu, na qual o método foi configurado em detalhes, servindo de orientação e principal referência até os dias atuais. Como refere Triviños (1987, p. 159), é esta “a obra verdadeiramente notável sobre a análise de conteúdo, onde este método, poder-se-ia dizer, foi configurado em detalhes, não só em relação à técnica de seu emprego, mas também em seus princípios, em seus conceitos fundamentais”. Esta obra teve grande impacto no Brasil e, de lá para cá, tem sido aplicada, criticada, ampliada e, sobretudo, ainda suscita questionamentos e controvérsias no meio acadêmico. Sem dúvida, essa evolução, marcada por períodos alternados de aceitação e de negação, despertando questionamentos e contradições, vai aperfeiçoando a técnica.

Na busca pela cientificidade e pela objetividade, própria da época histórica, a análise de conteúdo recorreu a um enfoque quantitativo num primeiro momento, pelo qual a análise das mensagens se fazia pelo cálculo de frequências. Contudo, logo essa deficiência unilateral cedeu lugar às análises qualitativas, possibilitando que o método fosse utilizado em ambas as abordagens, até mesmo, concomitantemente (Godoy, 1995).

Também na década de 1950, houve discussões a respeito da validade das técnicas quali e quantitativas, uma em detrimento da outra (Bardin, 2006). Mais de meio século depois, ainda se discutem tais questões; no entanto as controvérsias estão mais no nível da adequada apropriação da técnica de pesquisa de acordo com os seus propósitos, pois podem ser utilizadas paralelamente. A maior parte dos estudiosos que ainda tecem críticas a um ou outro tipo de abordagem (qualitativa ou quantitativa), o faz por conta do que Adorno denominou de fetichismo do método (Adorno \& Horkheimer, 1979) pois, adentrando-se no século XXI, discussões como essa já deveriam estar superadas ou, pelo menos, em fase de superação.

Nesse sentido, a análise qualitativa não rejeita toda e qualquer forma de quantificação (Bardin, 2006). Por mais que tenha na sua origem a quantificação, logo se compreendeu que esta técnica pode 
ser aplicada também na análise qualitativa, pois sua característica é a inferência (variáveis inferidas a partir de variáveis de inferência no nível da mensagem), quer estas estejam baseadas ou não em indicadores quantitativos.

Fielding (1999), com base nos manuais de metodologia qualitativa de Norman Denzin e Yvonna Lincoln, afirma que nos últimos tempos os métodos qualitativos têm desfrutado de grande legitimidade na academia, por mais que seja um campo marcado por controvérsias. Corrobora-se o autor, quando indica os trabalhos de Denzin e Lincoln para entender a amplitude das abordagens contemporâneas dos métodos qualitativos de pesquisa.

Não se tem como pretensão, neste ensaio teórico, o esgotamento da discussão a respeito das diferentes abordagens metodológicas. No entanto, como o foco é a pesquisa qualitativa, cabe salientar que nesta o investigador é o instrumento principal e o maior interesse está no processo, não nos resultados ou produtos, além de que os investigadores qualitativos tendem a analisar os dados de forma indutiva. Por fim, como afirma Flick (2009, p. 276), “a interpretação de dados é a essência da pesquisa qualitativa, embora sua importância seja vista de forma diferenciada nas diversas abordagens".

Da mesma forma, não se pretende o detalhamento histórico do método da análise de conteúdo, por já ser retratado em muitos estudos por diferentes autores. No entanto, após essa breve explanação histórica, cabe ressaltar, também fazendo uso das palavras de Bardin (2006, p. 158), que "a análise de conteúdo é um método que pode ser aplicado tanto na pesquisa quantitativa como na investigação qualitativa, mas com aplicação diferente”.

\section{Diferentes técnicas de análise de dados}

O conhecimento dos diversos métodos de análise de dados existentes torna-se indispensável para que o pesquisador tenha condições de realizar a escolha mais adequada ao que se propõe estudar, visando ao avanço na temática e, consequentemente, no campo de estudo. Tal premissa se torna essencial também aos pesquisadores do campo da administração. Não se tem como pretensão apregoar que os pesquisadores necessitam conhecer todos os métodos de análise de dados em profundidade, até em razão da sua significativa variedade. No entanto, um conhecimento amplo das diferentes técnicas de análise de dados torna-se pertinente, para que as escolhas possam ser realizadas de maneira mais apropriada, tanto para a temática estudada como para aos propósitos do pesquisador e, também, para o campo de pesquisa. No que tange aos diferentes métodos de análise de dados, Peräkylä (2008, p. 353, tradução nossa), por mais que enfatize mais a análise de textos, refere:

Há, na verdade, muitos métodos de análise de textos que o pesquisador pode escolher. O grau nos quais eles envolvem conjuntos predefinidos de procedimentos varia; alguns deles são bem extensos, enquanto em outros a ênfase é mais sobre a pressuposição teórica com relação aos mundos sociais e culturais aos quais o texto pertence.

Diante do exposto, vale salientar que a força da argumentação (a análise dos dados êmicos) é que traz consistência em qualquer análise qualitativa. Contudo, isso exige um trabalho bastante denso por parte do pesquisador, no próprio sentido de deixar claro o porquê da escolha de determinada técnica de análise para a investigação do objeto específico, demarcando as condições de interpretação.

Por mais que o foco deste ensaio teórico tenha sido a análise de conteúdo, não se afirma que se constitui na técnica de análise de dados mais apropriada ou legitimada, e, sim, que se insere como uma técnica em crescente utilização e legitimação nos estudos qualitativos no campo da administração. Contudo, por mais que não constitua o foco deste trabalho, parece pertinente revisar rapidamente as técnicas de análise de dados mais utilizadas nos estudos organizacionais. Desse modo, apresenta-se breve contextualização a respeito da análise do discurso, análise da conversa e análise de narrativas.

A análise do discurso consiste numa técnica de análise que explora as relações entre discurso e realidade, verificando como os textos são feitos, carregando significados por meio dos processos 
sociais. Os textos podem ser considerados tanto uma unidade discursiva como manifestação material do próprio discurso; podem ter grande variedade de formas, ou seja, escritos, palavras, fotos, símbolos, artefatos, entre outros. Os textos só possuem significância, considerando a natureza de sua produção, disseminação e consumo. Dessa forma, Phillips e Hardy (2002) referem que a análise do discurso é, simultaneamente, método e metodologia e é sempre uma análise crítica. Por sua vez, Bardin (2006) enquadra a análise do discurso como pertencente ao campo da análise de conteúdo, salientando limitações inerentes a essa primeira.

A respeito, considera-se que a análise de conteúdo procura relatar os significantes e a análise de discurso, o significado. Para tanto, esta última faz uso da linguística. Por mais que, aparentemente, a análise de conteúdo e a linguística tenham a linguagem como objeto, há uma distinção entre língua e palavra que faz toda a diferença. Dessa forma, o objeto na linguística é a língua e o da análise de conteúdo, a palavra (Bardin, 2006).

Pode-se dizer que a análise do discurso é uma vertente da análise da conversa, havendo até visões diferentes a respeito (Flick, 2009). No que tange à análise da conversa, refere o autor que "tem menor interesse pela interpretação do conteúdo de textos que tenham sido produzidos explicitamente para fins de pesquisa, como, por exemplo, as respostas da entrevista. Em vez disso, seu interesse concentra-se na análise formal de situações cotidianas” (p. 299). Como um dos pontos-chave da técnica o autor chama atenção para o fato de que a análise da conversa "foi originalmente planejada para o estudo da interação cotidiana com um foco formal” (p. 305).

Por mais que a análise da conversa carregue a estrutura da argumentação produtiva e tenha a língua como objeto de análise, apresenta características mais positivistas. Flick (2009) afirma que a análise do discurso aproxima-se mais dos estudos das ciências sociais do que a análise da conversa.

No que tange à análise de narrativas, utiliza-se das narrativas (falas) dos participantes da pesquisa. De um modo mais geral, a vida é considerada como narrativa para permitir a análise da construção narrativa da realidade (Bruner, 1987, 1991) sem a utilização de um procedimento de coleta de dados que vise expressamente à indução de narrativas (Flick, 2009, p. 307). Como qualquer uma das outras técnicas de análise de dados aqui apresentada, também a análise de narrativas segue uma sequência de etapas, visando à análise prática. Como afirmam Bauer e Gaskell (2008, p. 90), "as narrativas se tornaram um método de pesquisa muito difundido nas ciências sociais”.

Apesar da simplificação ao se apresentar rapidamente algumas das técnicas de análise de dados mais utilizadas em ciências sociais, este debate não é simples, abrangendo muitos aspectos que não são aqui apresentados em razão de não ser o propósito deste trabalho. Para finalizar essa rápida contextualização dos métodos, cabe retomar Thompson (1995), o qual deixa explícito que, por mais que os métodos de análises sejam rigorosos e sistemáticos, não abolem a necessária construção criativa do significado, ou seja, uma interpretação apropriada do que está sendo dito ou representado. Essa é uma premissa válida para toda e qualquer técnica de análise de dados, principalmente nos debates contemporâneos.

\section{Debates Contemporâneos e Críticos em Relação a Análise de Conteúdo}

Partindo do princípio de que qualquer posicionamento crítico só é viável diante de conhecimento prévio, abordam-se a seguir tanto as potencialidades como as limitações da técnica análise de conteúdo, possibilitando uma discussão contemporânea a respeito da validade e da confiabilidade, aspectos essenciais na busca da legitimidade de uma pesquisa. 


\section{Potencialidades da análise de conteúdo}

Triviños (1987) salienta que a análise de conteúdo constitui-se num conjunto de técnicas. Para tanto, o pesquisador necessita "possuir amplo campo de clareza teórica. Isto é, não será possível a inferência, se não dominarmos os conceitos básicos das teorias” (1987, p. 160). O pesquisador que admite a existência de diferentes lógicas de pesquisa, mantendo-se em consonância com o método adotado, denota coerência, revelando grande potencial da pesquisa ao saber explicitar a sua opção metodológica e todo o procedimento desenvolvido na construção de sua investigação.

A análise de conteúdo constitui-se num método específico que parece mais claro em razão da elaboração esquemática que o acompanha (passo a passo), tornando-o mais fácil e menos ambíguo, "devido à possível redução do material anteriormente delineado. As muitas regras formuladas destacam essa impressão de uma maior clareza e ausência de ambiguidade” (Flick, 2009, p. 294). Tal aspecto também pode ser visto como uma das potencialidades da técnica. Como afirmam muitos pesquisadores, a análise de conteúdo "reduz a complexidade de uma coleção de textos. A classificação sistemática e a contagem de unidades do texto destilam uma grande quantidade de material em uma descrição curta de algumas de suas características” (Bauer \& Gaskell, 2008, p. 191).

Flick (2009) destaca também a vantagem que tal método analítico possui sobre os métodos mais indutivos, visto que a formalização do procedimento origina categorias que facilitam a comparação entre os diferentes casos. No entanto, o pesquisador não deve adentrar no campo de pesquisa desprovido de bagagem teórica. A priori, por mais que não sejam estabelecidas hipóteses nas pesquisas qualitativas, certas categorias precisam ser criadas, ainda que não sejam definitivas e únicas.

Afirma Triviños (1987) que a análise de conteúdo, além de método de análise único, pode servir de auxiliar em pesquisas mais complexas, fazendo parte de uma visão mais ampla, como no caso do método dialético. No entanto, para que o método realmente atinja tal envergadura, faz-se necessário considerar o contexto das análises, não podendo o pesquisador ater-se apenas aos aspectos superficiais e/ou manifestos dos dados coletados. Na realidade, como adverte Flick (2009, p. 298), a noção de contexto (contexto discursivo e contexto interativo local) já é "mais ou menos indiscutível na pesquisa qualitativa”.

Nesse mesmo sentido, Thompson (1995) aponta a importância do contexto e da história nas análises científicas. De forma semelhante, Bateson (2000) salienta a ideia do contexto, afirmando que considerar conteúdo sem o contexto, qualquer análise torna-se falha; por isso, há a necessidade de olhar o sistema como um todo, contrapondo-se à fragmentação da ciência. Também Chase (2008) confia na investigação com visão interdisciplinar, defendendo o estudo dos indivíduos em seus próprios contextos social e histórico.

Tais aspectos de uma investigação podem se manifestar-se por meio de formas simbólicas, as quais necessitam de macrointerpretação. Formas simbólicas são construções significativas interpretadas e compreendidas por pessoas, que as produzem e recebem. Mas elas são também construções estruturadas de maneiras definidas e inseridas em condições sociais e históricas específicas (Thompson, 1995).

O autor não cita a análise de conteúdo como forma de investigação hermenêutica em suas várias fases: interpretação doxa, análise sócio-histórica, análise formal ou discursiva e interpretação/reinterpretação. No entanto, deixa claro que uma variedade de métodos de pesquisas pode fazer parte da hermenêutica, tornando-se mais adequado que outros de acordo com o objetivo da análise e, também, com as circunstâncias específicas do estudo. Dessa forma, pensa-se que a análise de conteúdo pode ser incluída na fase da análise formal ou discursiva citada por Thompson (1995), visto que as formas simbólicas por ele citadas, estão presentes também na análise de conteúdo. Tais formas simbólicas devem ser percebidas e analisadas apropriadamente. Para tanto, o contexto e também a história, como afirmam Thompson (1995), Bateson (2000), Chase (2008), entre outros, tornam-se importantíssimos para potenciar a técnica. Ainda em relação às formas simbólicas, Thompson (1995, p. 357) salienta que: 
o estudo das formas simbólicas é fundamental e inevitavelmente um problema de compreensão e interpretação. Formas simbólicas são construções significativas que exigem uma interpretação; elas são ações, falas, textos que, por serem construções significativas, podem ser compreendidas.

Nesse sentido, defende o autor que "os métodos podem ajudar o analista a ver a forma simbólica de uma maneira nova” (Thompson, 1995, p. 375). Acredita-se que a análise de conteúdo siga essa mesma lógica, pela qual o pesquisador culmina por ampliar a sua visão, ao seguir os passos propostos pelo método. No entanto, como nem o método da análise de conteúdo propõe, o pesquisador não pode deixar de interpretar, utilizando-se da construção criativa, pois o simbolismo exige, necessariamente, a interpretação. Trabalhada nesses termos, a análise de conteúdo apresenta-se como de grande potencialidade para o avanço das pesquisas no campo da administração.

Freitas, Cunha e Moscarola (1997, p. 108) pontuam que, para uma análise de conteúdo ter valor, existem alguns pré-requisitos, como: qualidade da elaboração conceitual feita a priori pelo pesquisador, da exatidão com que ela será traduzida em variáveis, do esquema de análise ou das categorias e, em definitivo, da concordância entre a realidade a analisar e estas categorias.

Diante do exposto, pode-se afirmar que, caso a utilização da análise de conteúdo tenha como única preocupação seguir um passo a passo, sem considerar os aspectos apontados neste estudo, a técnica pode apresentar-se falha. Com o intuito de que o pesquisador não se deixe engendrar pelas limitações que a própria técnica pode apresentar, faz-se uma descrição dessas na sequência.

\section{Limitações da análise de conteúdo}

Como toda técnica de análise, certas limitações também são inerentes à análise de conteúdo, as quais são apontadas por diferentes autores. Uma das críticas mais fortes e recorrentes à análise de conteúdo é o fato de carregar um ideário de metodologia quantitativa. Nesse sentido, a categorização própria do método, um tanto esquemática, pode obscurecer a visão dos conteúdos, impedindo o alcance de aspectos mais profundos do texto (Flick, 2009).

De um lado, Flick (2009, p. 294) destaca que muitas vezes falta profundidade nas análises e se constitui no uso de paráfrases, "utilizadas não apenas para explicar o texto básico, mas também para substituí-lo - sobretudo na síntese da análise de conteúdo”. De outro lado, Thompson (1995) chama atenção para o fato de o pesquisador não ser neutro, referindo-se ao "mito do receptor passivo" (p. 409). Na realidade, o campo é tanto campo-objeto como campo-sujeito, em que "as formas simbólicas são pré-interpretadas pelos sujeitos que constituem esse campo” (p. 364). Dessa forma, a inferência do pesquisador, a qual se faz necessária, não é totalmente neutra; no entanto ele deve procurar interferir minimamente de maneira pessoal. Isso não quer dizer ser acrítico ou não fazer inferências, aspectos que uma análise de conteúdo em pesquisas qualitativas exige.

Nesse sentido, em virtude de a análise de conteúdo exigir inferência do pesquisador em suas diferentes fases, a neutralidade pode ser considerada uma limitação. Por outro lado, como refere Thompson (1995), não se pode esquecer que o objeto de análise constitui construção simbólica significativa, o que pode se reverter em validação para a pesquisa, fugindo das críticas das análises positivistas.

Na busca de superação desse limite, o pesquisador, entre outras preocupações, deve assegurar-se detalhando os procedimentos adotados na abordagem, visando garantir a validade da sua análise. Não se está advogando uma busca rigorosa do método ou que o pesquisador não realize nenhuma inferência, fazendo uso da flexibilidade necessária, e, sim, que tome cuidado, tanto em detalhar como em cumprir as etapas que constituem o método, evitando tanto o positivismo como o idealismo. Vale também para a análise de conteúdo o que Thompson (1995, p. 375) advoga a respeito da construção criativa que a forma simbólica exige: 
por mais rigorosos e sistemáticos que os métodos da análise formal ou discursiva possam ser, eles não podem abolir a necessidade de uma construção criativa do significado, isto é, de uma explicação interpretativa do que está representado ou do que é dito.

Sobretudo, é preciso considerar que toda construção criativa não pode estar desvinculada da análise do contexto e da história, como bem salientam Thompson (1995), Bateson (2000) e Chase (2008). Este último também aponta a falta de visão interdisciplinar como outra limitação de alguns pesquisadores que utilizam a técnica. Todavia Denzin e Lincoln (2008) explicitam, também por intermédio de outros teóricos, que a falta ou fraca análise contextual é um dos grandes limitantes das análises em pesquisas qualitativas.

Outra limitação da análise de conteúdo é o fato de ter privilegiado as formas de comunicação oral e escrita, excluindo, por vezes, outros meios de comunicação, também significativos e que podem fazer total diferença conforme a temática em análise (Godoy, 1995). Nesse sentido, mais uma vez a criatividade e a flexibilidade fazem-se necessárias (Denzin \& Lincoln, 2008; Flick, 2009), para não limitar a pesquisa. Retoma-se que também Thompson (1995) salienta a importância da criatividade nas análises dos resultados das pesquisas e Popper (1992) fala da necessária flexibilidade.

Por fim, cabe salientar que a análise de conteúdo possibilita a utilização de diferentes estratégias de análise no seu desenvolvimento metodológico; mas, ao mesmo tempo, sinaliza os seus limites e falácias subjacentes. Dessa forma, a busca por critérios de validade e confiabilidade constituise num caminho para a superação das limitações, inerentes ou não à própria técnica.

\section{Validade e Confiabilidade: Questões Essenciais na Legitimação de uma Pesquisa}

A validação dos resultados de uma pesquisa culmina numa exigência básica em qualquer campo científico, seja essa de caráter qualitativo, seja quantitativo. No entanto o processo de validação e a confiabilidade não têm a mesma conotação nessas duas abordagens. "No geral, porém, confiabilidade e generalização desempenham um papel menor na investigação qualitativa” (Creswell, 2007, p. 199). Contudo, isso não significa afirmar que as pesquisas qualitativas não precisam apresentar critérios de validação ou não possam desempenhar papel de generalização, por mais que busquem antes a explicação e a confirmação ou não de pressupostos, culminando na apresentação de proposições, as quais podem ser sintetizadas num constructo teórico. Assim, na pesquisa qualitativa se fala mais na transferibilidade do que na generalização, sendo que a dificuldade de generalização é inerente à pesquisa qualitativa, não podendo ser destacada como limitação.

Por mais que se tenha destacado a pesquisa qualitativa no transcorrer deste ensaio teórico, como já assinalado anteriormente, não se tem como pretensão minimizar a importância da pesquisa quantitativa, tampouco desconsiderar a legitimidade de pesquisas que utilizam método misto. Assim como Bauer e Gaskell (2008), considera-se a análise de conteúdo uma técnica hibrida. Muitos outros autores também assinalam que as abordagens qualitativas e quantitativas podem ser complementares (Bardin, 2006; Bauer \& Gaskell, 2008; Creswell, 2007; Flick, 2009; Minayo, 2001; Thompson, 1995; Yin, 2001). E, em alguns estudos, isso é até desejável e confere validade e confiabilidade à pesquisa.

As etapas inerentes à pesquisa qualitativa e à quantitativa são praticamente as mesmas, ambas serão definidas e desenvolvidas de acordo com as diferentes matrizes paradigmáticas escolhidas. Portanto, para cada um desses métodos, existem critérios próprios de confiabilidade e de validação, tanto interna como externamente. $\mathrm{O}$ foco deste ensaio teórico concentra-se na pesquisa qualitativa em virtude da opção tomada e justificada desde o início deste trabalho.

Richardson (1999) destaca a importância tanto da confiabilidade como da validade interna e externa. Afirma que pesquisas científicas devem cumprir critérios científicos e que a apresentação de critérios de confiabilidade e validade culminam por ser uma exigência da pesquisa séria e ética. Para o autor, confiabilidade "indica a capacidade que devem ter os instrumentos utilizados de produzir 
medições constantes, quando aplicados a um mesmo fenômeno". Yin (2001, p. 60) destaca que "o propósito da confiabilidade é minimizar os erros e os vieses de um estudo". Por sua vez, para Richardson (1999, p. 87), a validade "indica a capacidade de um instrumento produzir medições adequadas e precisas para chegar a conclusões corretas, assim como a possibilidade de aplicar as descobertas a grupos semelhantes não incluídos em determinada pesquisa”.

Buscando assegurar a validade interna em pesquisas qualitativas, Creswell (2007, p. 207) faz referência às seguintes estratégias: "triangulação de dados”, "verificação de membro”, "observações a longo prazo e repetidas no local de pesquisa”, "exame dos pares", "modos de pesquisa participatórios" e "esclarecimento dos vieses do pesquisador". A triangulação tem sido amplamente discutida e muito bem aceita, tanto na coleta como na análise de dados e "supera as limitações de um método único, por combinar diversos métodos e dar-lhes igual relevância” (Flick, 2009, p. 32). O autor não se refere apenas à triangulação metodológica, mas também salienta a importância da "triangulação dos dados", “triangulação do investigador” e da "triangulação da teoria” (Flick, 2009, p. 361).

No que diz respeito à triangulação metodológica, apesar de importante para a validação dos resultados das pesquisas, torna-se auspicioso que cada técnica de análise seja trabalhada de acordo com os seus próprios princípios, para que só após sejam realizados cruzamentos entre os resultados obtidos na aplicação de cada uma (Denzin \& Lincoln, 2008).

Diante da importância da validade e da confiabilidade de uma pesquisa, Creswell (2007, p. 200) expõe oito estratégias para confirmar a exatidão dos resultados em pesquisa qualitativa: "faça uma triangulação de diferentes fontes de informações de dados", "use conferências dos membros para determinar a precisão dos resultados", "use descrição rica e densa para transmitir os resultados", "esclareça os vieses que o pesquisador traz para o estudo", "apresente informações negativas ou discrepantes que vão contra os temas", "passe um tempo prolongado no campo", "use interrogatório de pares para aumentar a precisão do relato", "use um auditor externo para rever o projeto todo". Enfim, o pesquisador precisa saber que existem diferentes lógicas de pesquisa e que se manter em consonância com o método adotado é sinal de coerência. Por conseguinte, o saber explicitar a sua opção metodológica e todo o procedimento desenvolvido na construção de sua investigação também credita validade e confiabilidade ao estudo. Contudo assevera Triviños (1987, p. 170):

Os resultados, para que tenham valor científico, devem reunir certas condições. A coerência, a consistência, a originalidade e a objetivação (não objetividade), por um lado, constituindo os aspectos do critério interno da verdade, e, por outro, a intersubjetividade, o critério externo.

Nesse mesmo sentido, Bauer e Gaskell (2008, p. 191) sustentam:

A validade da AC deve ser julgada não contra uma 'leitura verdadeira' do texto, mas em termos de sua fundamentação nos materiais pesquisados e sua congruência com a teoria do pesquisador, e à luz de seu objetivo de pesquisa. Um corpus de texto oferece diferentes leituras, dependendo dos vieses que ele contém.

Cabe salientar que, ao se trabalhar com a análise de conteúdo, de acordo com Bardin (2006), o cuidado com a descrição e execução de cada uma das fases da análise, por mais que se mantenham a flexibilidade e a criatividade, caracteriza-se como forma de gerar confiabilidade e validade. Flick (2009) enfatiza o cuidado com o detalhamento do processo da pesquisa como um todo (o planejamento da pesquisa), como também a adequada exposição dos dados (incluindo a redação) na busca da confiabilidade, ou seja, na busca pela validação e confiabilidade, uma boa redação dos resultados da pesquisa, na qual se torna explícita uma boa organização dos dados, é fundamental.

Por fim, salienta-se outra forma de validação dos resultados de uma pesquisa, que é a adequada utilização de softwares, tanto quantitativos quanto qualitativos. Como este ensaio teórico está com o foco direcionado à pesquisa qualitativa, parece pertinente destacar as novas tecnologias que facilitam a análise de conteúdo com abordagem qualitativa. 


\section{Novas tecnologias: softwares que facilitam a análise de dados qualitativos}

As novas tecnologias têm cada vez mais influenciado nas pesquisas. Desde a década de 1980 a utilização da tecnologia faz parte tanto da coleta como da análise de dados em pesquisas científicas, alterando os seus padrões. Também as pesquisas qualitativas podem fazer uso de programas para análise de dados, sem que o pesquisador espere que estes realizem o trabalho de análise automaticamente; na realidade, apenas auxiliam na pesquisa. Entre tais programas auxiliares para a análise de dados qualitativos, citam-se: NUD*IST (gerenciador de referências para biblioteca pessoal), ATLAS*ti (planejar projetos) e MAXqda (importa e exporta materiais de diferentes fontes (Flick, 2009)).

Como evidencia o autor, na tentativa de facilitar a análise das comunicações, têm-se buscado algumas alternativas em meios informacionais e existem mais de vinte e cinco programas para análise qualitativa na atualidade. Além dos programas citados por Flick (2009), destaca-se que o software NVivo vem sendo cada vez mais utilizado no campo da administração, constituindo meio válido de análise de dados qualitativos. Cabe salientar que tal programa exige um grande envolvimento do pesquisador, potencializando os resultados da pesquisa, com o aumento do alcance e da profundidade das análises. Para maior conhecimento de tal programa computacional, sugere-se o acesso à página eletrônica, no endereço: <http://caqdas.soc.surrey.ac.uk>. Também tem sido utilizado com certa frequência, na própria análise de conteúdo, o sistema Sphinx (Freitas et al., 1997).

Em razão de que a análise de conteúdo constitui-se num método de tratamento de comunicações, que pode ser bastante amplo conforme os objetivos e delineamento metodológicos de uma pesquisa, emerge a necessidade do emprego de técnicas computacionais, estatísticas ou não. Nesse sentido, tanto os softwares quantitativos (ex: SPSS) como os qualitativos (ex: NVivo) facilitam e qualificam o processo de análise.

O Nvivo, além da finalidade básica de facilitar e agilizar as análises, tem a função tanto de validar como de gerar confiança, qualificando o material coletado. Contudo, como qualquer programa computacional, além da necessidade da utilização correta, os dados que o alimentam têm de ser apropriados, sob o risco de se ter um corpus falho.

No que tange às pesquisas quantitativas, a utilização de software tem sido mais comum, antiga, conhecida e até mais bem aceita no meio acadêmico. No entanto o momento atual evidencia uma tendência de as pesquisas qualitativas também fazerem uso da informática, visando à agilização e qualificação do material de análise. Como refere Creswell (2007, p. 197), o material a ser analisado (comunicação) "pode ser melhorado com o uso de programas de computador com software qualitativo”. O próprio Bardin (2006, p. 37) admite as novas tecnologias como facilitadoras, afirmando que o procedimento de codificação do que é comunicado é simples, "se bem que algo fastidioso quando feito manualmente”.

Por fim, torna-se pertinente reafirmar o fato de que a utilização de softwares apenas serve para facilitar a análise e a interpretação, não eximindo a atuação ativa do pesquisador na adoção de um método de análise coerente e pertinente ao tema e à orientação epistemológica. Contudo percebe-se a ampliação das possibilidades de utilização da análise de conteúdo nos estudos organizacionais, na utilização de softwares qualitativos, os quais não têm o intuito de quantificar ou criar um viés positivista.

\section{Possibilidades da Utilização da Análise de Conteúdo no Campo da Administração}

Sabiamente, afirma Minayo (2001, p. 79) que “o produto final da análise de uma pesquisa, por mais brilhante que seja, deve ser sempre encarada de forma provisória e aproximativa”. Tal posicionamento toma como base que, "em se tratando de ciência, as afirmações podem superar 
conclusões prévias a elas e podem ser superadas por outras afirmações futuras”. Na realidade, esse é o percurso da ciência. Como afirma Kuhn (1991), o conhecimento científico não cresce de modo cumulativo e contínuo; ele é descontínuo e opera em saltos qualitativos.

Nesse sentido, Popper (1992) aponta uma concepção inovadora do método científico mediante a racionalidade crítica e o aspecto de flexibilidade, resultando em ideias de progresso científico, que podem ser aplicadas ao método de fazer ciência em Administração. Na sua obra Em busca de um mundo melhor, Popper (1992) defende mais uma vez a busca da verdade, não a busca da certeza, a qual não deve se constituir numa meta científica. No entanto na Administração ainda se percebe a utilização de métodos de análise de dados, até mesmo a análise de conteúdo, na busca da certeza por meio da indução, como as aplicações de modelos, por exemplo.

A assimilação das ideias de Popper (1992, 1999, 2004) por parte dos estudiosos em Administração colabora sobremaneira, possibilitando que os métodos desenvolvidos nas pesquisas e publicações sejam questionados, para que não continuem seguindo numa mesma lógica positivista e indutiva. Dessa maneira, pode-se vislumbrar uma contribuição como ciência mais consciente e útil para a construção do conhecimento no campo da administração e para a sociedade como um todo, pois todos podem e devem contribuir para o aperfeiçoamento do universo, na busca de um mundo melhor, como defende o autor.

O método crítico e a consequente discussão crítica (antipositivista) norteiam os escritos de Popper (1992, 1999, 2004), para o qual o princípio da racionalidade é limitado, visto que não consegue explicar muitas coisas. Nesse sentido, denuncia o fato de as pessoas tenderem a procurar regularidades que levam ao pensamento e/ou comportamento dogmáticos, os quais se procura preservar a qualquer custo, limitando, consequentemente, a atitude crítica. $\mathrm{O}$ autor não acredita em verdades definitivas, mas em conhecimento hipotético e problemático. Dessa forma, não aceita as teorias como modelos, pois a teoria está acima de qualquer modelo, o qual acaba por ser uma simplificação da realidade, que representa certas condições que não podem ser consideradas leis universais.

Diante dessa lógica de mudanças permanentes na ciência, resultados de pesquisas como provisório e aproximativo (Minayo, 2001) e crescimento descontínuo do conhecimento científico (Kuhn, 1991), percebe-se que alternativas metodológicas devem ser mais bem discutidas e aplicadas também nos estudos organizacionais. Nesse sentido, a análise de conteúdo apresenta-se como técnica de análise de dados cada vez mais legitimada nas pesquisas realizadas no campo da administração, mas que ainda necessita ser mais bem debatida e ampliada em suas aplicações, visando apresentar maior confiabilidade e validade no mundo científico.

Diante do exposto e no sentido proposto por Popper (1992), na busca da verdade, (não das certezas), sabe-se que a análise de conteúdo é considerada como técnica de análise qualitativa muito pertinente aos estudos organizacionais, possibilitando a ampliação da qualidade da pesquisa qualitativa no campo da administração em suas diferentes áreas.

\section{Conclusão}

Novas e velhas questões apresentam-se neste início de século, no qual ocorrem intensas e velozes mudanças carregadas de historicidade. Desse modo, as diferentes áreas disciplinares de estudo no campo da administração também passam por inquietações, revisões e reformulações, o que não é diferente em relação aos métodos de análises científicas.

No que diz respeito à escolha das técnicas de análise de dados de pesquisa, múltiplas escolhas podem ser feitas e, em alguns casos, devem ser múltiplas para que se proporcione uma aproximação mais adequada ou abrangente ao tema a ser estudado. O campo da pesquisa em administração não nega nem minimiza a importância da coexistência de métodos; contudo a coerência entre esses é premissa básica. 
Por isso apresentam-se de maneira objetiva, algumas respostas (provisórias, decerto) às questões formuladas de início. Em primeiro lugar, em relação à contribuição da análise de conteúdo para as pesquisas qualitativas no campo da administração. Percebe-se claramente a sua importância para as pesquisas com essa abordagem; até mesmo muitos estudos vêm sendo desenvolvidos nesse sentido, legitimando a análise de conteúdo em estudos qualitativos nas diversas áreas da administração. Quanto aos desafios dessa perspectiva, ficou evidenciado que estes são contínuos e provocam o aprimoramento da técnica de análise de conteúdo; a perspectiva de sua aplicação profícua é cada vez maior, legitimando-se nos estudos organizacionais pela forma como a técnica é utilizada. No que concerne à possibilidade de a análise de conteúdo fazer parte de uma visão mais ampla, para além da influência positivista que sofre, ficou evidente a sua potencialidade para tanto, desde que os pesquisadores trabalhem com o método de forma coerente, ética, reflexiva, flexível e crítica, além de considerarem seriamente o contexto e a história nos quais a pesquisa se insere. Reitera-se, portanto, a análise de conteúdo como técnica de análise de dados rica, importante e com grande potencial para o desenvolvimento teórico no campo da administração, principalmente nos estudos com abordagem qualitativa.

Por fim, espera-se que este ensaio teórico contribua para resgatar algumas particularidades da técnica análise de conteúdo em pesquisas qualitativas, salientando seu potencial de aplicação. A análise de conteúdo pode ajudar aqueles pesquisadores que pretendem desenvolver estudos no campo da administração segundo uma abordagem analítica crítica e reflexiva, aventurando-se na aplicação da análise de conteúdo como técnica de análise de dados qualitativos, ou mesmo mistos, no sentido de complementação. Neste trabalho não se procurou simplesmente descrever o método de análise de conteúdo, pois há muitas outras variantes que precisariam ser mais bem exploradas. Na realidade, teve-se como objetivo discutir, em nível metodológico, algumas peculiaridades da análise de conteúdo, com base numa visão crítica, que integra os conceitos mais importantes para dar ensejo às diversas possibilidades de pesquisa e à apropriada (no sentido de não ingênua) utilização da técnica.

\section{Referências}

Adorno, T. W., \& Horkheimer, M. (1979). Sociologica. Madrid: Taurus.

Alves-Mazzotti, A. J., \& Gewandsznajder, F. (1998). O método nas ciências naturais e sociais: pesquisa quantitativa e qualitativa (2a ed.). São Paulo: Pioneira.

Bardin, L. (2006). Análise de conteúdo (L. de A. Rego \& A. Pinheiro, Trads.). Lisboa: Edições 70. (Obra original publicada em 1977)

Bateson, G. (2000). Steps to a ecology of mind: collected in anthropology, psychiatry, evolution, and epistemology. Chicago: University of Chicago Press.

Bauer, M., \& Gaskell, G. (Eds.). (2008). Qualitative researching with text, image, and sound. London: Sage.

Bruner, J. (1987). Life as narrative. Social Research, 54, 11-32.

Bruner, J. (1991). The narrative construction of reality. Critical Inquiry, 18(1), 1-21.

Chase, S. E. (2008). Narrative inquiry: multiple lenses, approaches, voices. In N. K. Denzin \& Y. S. Lincoln (Eds.), Collecting and interpreting qualitative materials (pp. 57-94). Los Angeles: Sage.

Chizzotti, A. (2006). Pesquisa em ciências humanas e sociais (8a ed.). São Paulo: Cortez. 
Clegg, S. R., Hardy, C., \& Nord, W. R. (Orgs.). (2001). Handbook de estudos organizacionais (Vol. 2). São Paulo: Atlas.

Creswell, J. W. (2007). Projeto de pesquisa: métodos qualitativo, quantitativo e misto (2a ed., L. de O. Rocha, Trad.). Porto Alegre: Artmed. (Obra original publicada em 2003)

Dellagnelo, E. H. L., \& Silva, R. C. (2005). Análise de conteúdo e sua aplicação em pesquisa na administração. In M. M. F. Vieira \& D. M. Zovain (Orgs.), Pesquisa qualitativa em administração: teoria e prática (pp. 97-118). São Paulo: FGV.

Denzin, N. K., \& Lincoln, Y. S. (2000). Handbook of qualitative research (2nd ed.). Thousand Oaks: Sage publications.

Denzin, N. K., \& Lincoln, Y. S. (2006). O planejamento da pesquisa qualitativa: teoria e abordagens (2a ed., S. R. Netz, Trad.). Porto Alegre: Bookman.

Denzin, N. K., \& Lincoln, Y. S. (2008). Collecting and interpreting qualitative materials. Los Angeles: Sage.

Fielding, N. G. (1999). The norm and the text: Denzin and Lincoln's handbooks of qualitative method. Britsch Journal of Sociology, 50(3), 525-534. doi: 10.1111/j.1468-4446.1999.00525.x

Flick, U. (2009). Introdução à pesquisa qualitativa (3a ed., J. E. Costa, Trad.). São Paulo: Artmed. (Obra original publicada em 1995)

Freitas, H. M. R., Cunha, M. V. M., Jr., \& Moscarola, J. (1997). Aplicação de sistemas de software para auxílio na análise de conteúdo. Revista de Administração da USP, 32(3), 97-109.

Godoi, A. S., Bandeira-de-Melo, R., \& Silva, A. B. (2006). Pesquisa qualitativa nas organizações: paradigmas estratégias e métodos. São Paulo: Saraiva.

Godoy, A. S. (1995). Introdução à pesquisa qualitativa e suas possibilidades. Revista de Administração de Empresas, 35(2), 57-63.

Kuhn, T. S. (1991). A estrutura das revoluções científicas (3a ed.). São Paulo: Perspectiva.

Mattos, P. L. C. L. (2001, setembro). Teoria administrativa e pragmática da linguagem: perspectivas para problemas que afligem as relações entre acadêmicos e consultores, educadores e educandos. Anais do Encontro Nacional da Associação Nacional de Pós-Graduação e Pesquisa em Administração, Campinas, SP, Brasil, 25.

Mattos, P. L. C. L. (2006). Análise de entrevistas não estruturadas: da formalização à pragmática da linguagem. In C. K. Godoi, R. Bandeira-de-Mello, \& A. B. Silva (Orgs.), Pesquisa qualitativa em estudos organizacionais: paradigmas, estratégias e métodos. São Paulo: Saraiva.

Mayring, P. (1983). "Feminists" knowledge and the knowledge of feminisms: epistemology, theory methodology, and method. In T. May \& M. Williams (Eds.), Knowing the social world. Buckingham: Open University Press.

Minayo, M. C. S. (Org.). (2001). Pesquisa social: teoria, método e criatividade. Rio de Janeiro: Vozes.

Peräkylä, A. (2008). Analyzing talk and text. In N. K. Denzin \& Y. Lincoln (Eds.), Collecting and interpreting qualitative materials (pp. 351-374). Los Angeles: Sage.

Phillips, N., \& Hardy, C. (2002). Discourse analysis. London: Sage Publications.

Popper, K. (1992). Em busca de um mundo melhor (3a ed., T. Curvelo, Trad.). Lisboa: Fragmentos. (Obra original publicada em 1989) 
Popper, K. (1999). O mito do contexto: em defesa da ciência e da racionalidade. Lisboa: Edições 70.

Popper, K. (2004). Lógica das ciências sociais (3a ed., E. R. Martins, A. C. M. Acquarone Filho \& V. O. M. Silva, Trads.). Rio de Janeiro: Tempo Brasileiro. (Obra original publicada em 1902)

Richardson, R. J. (1999). Pesquisa social: métodos e técnicas (3a ed.). São Paulo: Atlas.

Shah, S. K., \& Corley, K. G. (2006). Building better theory by bridging the quantitative-qualitative divide. Journal of Management Sudies, 43(8), 1821-1835. doi: 10.1111/j.14676486.2006.00662.x

Thompson, J. B. (1995). Ideologia e cultura moderna: teoria social crítica na era dos meios de comunicação de massa (2a ed., Grupo de Estudos sobre Ideologia, Comunicação e Representações Sociais da Pós-Graduação do Instituto de Psicologia da PURCS, Trad.). Rio de Janeiro: Vozes. (Obra original publicada em 1990)

Triviños, A. (1987). Introdução à pesquisa em ciências sociais: a pesquisa qualitativa em educação. São Paulo: Atlas.

Vergara, S. C. (2003). Projetos e relatórios de pesquisa em Administração (4a ed.). São Paulo: Atlas.

Vergara, S. C. (2005). Método de pesquisa em administração. São Paulo: Atlas.

Yin, R. K. (2001). Estudo de caso: planejamento e métodos. Porto Alegre: Bookman. 